\title{
POLÍTICAS DE GÉNERO SOBRE MEDIOS DE COMUNICACIÓN. QUÉ EXISTE Y QUÉ DEBERÍA EXISTIR PARA REGULAR LOS CONTENIDOS Y EL LENGUAJE DE LA INFORMACIÓN PERIODÍSTICA
}

Dra. Isabel Tajahuerce Ángel ${ }^{1}$ : Universidad Complutense de Madrid. España.

isabeltj@ccinf.ucm.es

Dra. Graciela Padilla Castillo: Universidad Complutense de Madrid. España. gracielp@ucm.es

Acciones complementarias a la investigación: Medios de Comunicación, Igualdad y violencia de género. Formación de profesionales de la información y de la comunicación. Modalidad del proyecto: De investigación y desarrollo incluida trasnacional. Ámbito del proyecto: Nacional. Instituto de la Mujer. Dirigido por la Profesora Dra. Dña. Isabel Tajahuerce Ángel.

\section{RESUMEN:}

El presente artículo pretende estudiar las políticas de género sobre medios de comunicación en España, analizando qué existe y qué falta en esta materia. Plantea la necesidad de regulación del lenguaje por parte de las y los profesionales de los medios de comunicación, para lo cual se realiza un análisis histórico de las declaraciones de intenciones y de la legislación de igualdad que incluye a los medios de comunicación social y a las mujeres, desde la Declaración de los Derechos de la Mujer y de la Ciudadana de Olympe de Gouges, hasta las acciones más recientes de la ONU y de la Unión Europea. Se abre una reflexión sobre las leyes españolas actuales que tienen en cuenta a los medios de comunicación, incidiendo en aquellas parcelas donde falta normativa. Para ello, se utiliza como metodología una revisión bibliográfica pertinente y los resultados de un focus group o encuentro con periodistas de los medios de comunicación españoles más importantes, profesionales, en gran parte, sin formación específica en temas de género, que a puerta cerrada relatan sus experiencias, la línea editorial o el lenguaje sexista o no inclusivo que usan o se ven obligados a utilizar en algunas ocasiones, proponiendo nuevas líneas de

\footnotetext{
${ }^{1}$ Dra. Isabel Tajahuerce Ángel: Delegada del Rector para la Igualdad en la Universidad Complutense de Madrid. Doctora y Profesora Contratada Facultad de Ciencias de la Información, Universidad Complutense de Madrid.
} 
regulación ética y deontológica en materia de género y formación específica en comunicación y género.

PALABRAS CLAVE: Políticas de género - Medios de comunicación - Lenguaje - Sexismo - Periodismo - Perspectiva de Género - Formación con perspectiva de género - Feminismo.

\title{
GENDER POLICY IN MEDIA. WHAT THERE AND WHAT SHOULD EXIST TO REGULATE THE CONTENT AND THE LANGUAGE OF JOURNALISM INFORMATION
}

\begin{abstract}
:
This paper studies gender policy in the media in Spain, analyzing what exists and what is missing in this area. Specifically, we look for the regulation of communicators' and media's language. To do this, we propose a historical analysis of the statements of intent and equality legislation including the media and women, from the Declaration of the Rights of Woman and Citizen of Olympia de Gouges to the most recent actions of the UN and the European Union. Also, we reflect on the current Spanish laws, which include the media, focusing on those plots where foul rules. To do this, we use as methodology a relevant literature review and the results of a focus group meeting with Spanish journalists in major media. These professionals, largely without specific training on gender issues, recount in camera, the editorial line or sexist language used, or be forced to use sometimes, and propose new lines of ethical and deontological rules concerning gender, and Specific Training in Communication and Gender.
\end{abstract}

KEY WORDS: Gender Policy - Media - Language - Sexism - Journalism Gender Perspective - Training gendered - Feminism.

\section{INTRODUCCIÓN}

Los medios de comunicación social juegan un papel fundamental en las acciones políticas y en los cambios legislativos que se producen a finales del siglo XX y principios del XXI, en materia de igualdad y de lucha contra la violencia de género. No olvidemos que las mujeres siempre fueron periodistas, aunque no siempre el periodismo les abrió las puertas. Igualmente, fueron protagonistas de la noticia, pese a que se desautorizó su opinión de manera continuada. El periodismo, en el momento en que se convirtió en empresa y en sostén de un sistema económico que privó a las mujeres en sus inicios de derechos políticos, fue masculino y dio voz y visibilidad al poder patriarcal. Sin embargo, ellas no se rindieron y siguieron luchando, desde diferentes ámbitos, para que sus derechos y sus opiniones tuviesen reconocimiento e hicieron visible su realidad para transformarla. 
Este artículo estudia y reflexiona acerca de las políticas de género sobre medios de comunicación en España, analizando qué existe y qué falta en esta materia. Profundiza en la importancia que tiene la regulación sobre el lenguaje de las y los profesionales de los medios de comunicación, partiendo de un análisis histórico, de las declaraciones de intenciones y de la legislación de igualdad que incluye la libertad de expresión, los medios de comunicación social y a las mujeres, desde la Declaración de los Derechos de la Mujer y de la Ciudadana de Olympe de Gouges, hasta las acciones más recientes de la ONU y de la Unión Europea. Consideramos pertinente este análisis histórico para corroborar si ciertamente ha habido una evolución y un progreso en materia de políticas de género sobre medios de comunicación. Elegimos estos textos, y no otros, porque fueron los primeros en tratar el asunto y son hitos en la Historia de la Comunicación Social. Además, nos permiten reflexionar sobre si las políticas españolas de género tienen su origen en planteamientos de los movimientos de mujeres en España y en políticas concretas de determinados gobiernos, que asumen reivindicaciones de esos movimientos sociales, o responden a la inspiración o adhesión a políticas internacionales.

\section{OBJETIVOS}

Las leyes españolas actuales que contemplan los medios de comunicación, incidiendo en aquellas parcelas donde falta normativa, son: Ley Orgánica $1 / 2004$, de 28 de diciembre, de Medidas de Protección Integral contra la Violencia de Género y Ley Orgánica 3/2007, de 22 de marzo, para la igualdad efectiva y mujeres y hombre. Elegimos estas leyes, y no otras, porque son pioneras respecto al resto del mundo, porque han servido de inspiración a otros países miembros de la Unión Europea y a las demás leyes españolas actuales, que tratan políticas de género sobre medios de comunicación, a modo de pilar vertebrador. Desde el análisis de la realidad actual en esta materia, se nos plantea una serie de cuestiones cuya respuesta marcará los objetivos de este trabajo.

En primer lugar: ¿Cuáles son los primeros textos o iniciativas políticas internacionales que han examinado y regulado los asuntos de género en relación a los medios de comunicación? En segundo, ¿qué textos históricos inspiraron a textos posteriores y consiguieron intervenir eficazmente? Para acercar e igualar políticas internacionales en materia de género y medios de comunicación, ¿qué propuestas, iniciativas y textos han elaboradora las organizaciones internacionales?; ¿cómo ha sintetizado la regulación española esas directivas o consejos en cuanto a medios y género? Aunque existan esas leyes, ¿periodistas y profesionales de la comunicación las conocen, las aplican, detectan errores o exigen más legislación y formación al respecto?

Antes de responder a las cuestiones planteadas, consideramos imprescindible una breve introducción sobre el tema que nos ocupa, de una forma global y actual. Uno de los temas que ya no se cuestiona es el de la realidad de la violencia de género. La violencia no debe perpetuarse en las sociedades 
democráticas y su erradicación sólo es posible desde una intervención eficaz, que implique a diferentes agentes. La formación es imprescindible; explicar las causas de la violencia sólo es posible desde un profundo análisis de la desigualdad entre mujeres y hombres a nivel global, desde una perspectiva histórica y desde el estudio de las relaciones de poder. Sólo así se podrán elaborar políticas adecuadas para intervenir. Los medios de comunicación son agentes fundamentales de cambio. Por ello, la formación adecuada de profesionales, desde una perspectiva de género, es vital.

Las noticias sobre violencia contra las mujeres han tenido, históricamente, una perspectiva relacionada con el contexto social y legislativo, con las relaciones de poder y con la posición de las mujeres en las diferentes sociedades. En España, en los años 60, un periódico de sucesos especializado en "crónica negra", El Caso, comenzó a introducir sistemáticamente los asesinatos de mujeres, los llamados entonces, y durante mucho tiempo, "crímenes pasionales". Gil Ambrona (2008, p. 478) recuerda que todos los números trataban el asesinato de alguna mujer a manos de su marido. Según el autor, se pasó de cuatro o cinco casos anuales en los años 50, a más de medio centenar de casos recogidos, sólo en el año 1973. La violencia de género seguía siendo un problema negado, privado, familiar (Martínez García, 2008, p. 22). En El Caso no se trataba con la profundidad necesaria, porque no formaba parte de la política, de la sociedad ni, como hemos visto, de las leyes la igualdad de las mujeres.

Gil Ruiz (2007, p. 22) indica que, al estar relegada al ámbito privado, la violencia de género no entraba en los conceptos de delito o derechos individuales. Quedaba dentro de lo doméstico y en ese espacio, gozaba de una peligrosa inmunidad. La misma autora explica que era algo "normal" dentro del hogar, debido a los valores patriarcales que habían invisibilizado a la mujer como sujeto, cosificándola y legitimando su fragilidad, biológica y moralmente (2007, p. 181). Tendría que llegar el despertar legislativo y social, que denunciaría los casos de violencia de género, para sacarlos del ámbito privado, gracias a las reivindicaciones y acciones del movimiento feminista y a los estudios de género.

Una parte del despertar de la sociedad a la realidad de la desigualdad y de la violencia de género se debe a los medios de comunicación, que siempre han tenido esa doble vertiente de sostén del poder y de denuncia del mismo. Las noticias sobre mujeres asesinadas, desde una perspectiva de género, permitieron que el público tomara conciencia del problema y se diera cuenta de que estos delitos existían no sólo en arrabales urbanos, en el campo, o en las clases bajas (Lorente Acosta, en Marín López y Lorente Acosta, 2008, p. 29). Se trataba de una realidad generalizada, desconocida en toda su magnitud porque se producía, en la mayoría de los casos, tras la puerta cerrada; una realidad que afectaba a mujeres de todas las clases sociales, preparación cultural, situación económica, creencias religiosas e ideologías. La información se convierte en elemento clave y los medios de comunicación, en agentes 
imprescindibles para la prevención y para la detección. Era preciso informar desde un objetivo concreto: concienciar para prevenir y hacer entender a las mujeres que sufren violencia y a su entorno, de la necesidad de la denuncia.

Respecto a este punto, el magistrado Orga Larrés (2008, p. 27) expone que muy pocas víctimas se presentan en los juzgados o en la comisaría para denunciar, tras un proceso de reflexión y de planificación. Tienen miedo de hacer público su problema porque creen que la sociedad aún no está preparada para comprenderles. No les falta razón, porque todavía hoy, pese a las acciones realizadas, pese a las leyes y las políticas de igualdad, las víctimas siguen cargando con la culpa de ser víctima. Así, es fundamental que las y los periodistas tengan una formación adecuada para comprender que la violencia se produce porque existen relaciones de poder muy complejas. Sólo con formación podrán transmitir a la sociedad la realidad de la violencia de género, desde un marco adecuado que visibilice la historia de las mujeres y las causas de la discriminación que se mantiene en las sociedades contemporáneas, en muchas de manera sutil, contribuyendo a romper los estereotipos y a desterrar los prejuicios que mantienen la desigualdad y, por tanto, la violencia contra las mujeres.

\section{METODOLOGIA}

\subsection{Marco Metodológico}

Este artículo pretende estudiar las políticas de género sobre medios de comunicación en España, analizando qué existe y qué falta en esta materia. Como decíamos en la introducción, partimos de varios interrogantes que hilarán todo el artículo, analizando las principales políticas de género que han llevado a la situación actual española. Para ello, se realiza un análisis histórico de las declaraciones de intenciones y de la legislación, que sí tienen en cuenta la libertad de opinión y de expresión, así como a los diferentes medios de comunicación y a las mujeres, desde la Declaración de los Derechos de la Mujer y de la Ciudadana de Olympe de Gouges, que ya planteaba la cuestión de la opinión de las mujeres, hasta las acciones más recientes de la ONU y de la Unión Europea. Empleamos una revisión bibliográfica longitudinal, cuantitativa y cualitativa. Por otro lado, reflexionamos sobre la actual legislación española en materia de igualdad, que incorpora los medios de comunicación como agentes del cambio, tratando de completar aquellas parcelas donde falta normativa.

La metodología incluye un focus group, grupo focal o encuentro con periodistas españoles de los medios de comunicación más importantes, que no necesariamente tienen formación previa en materia de género, ni posiciones favorables a la igualdad de género, a puerta cerrada. La reunión con las y los profesionales tuvo lugar en la Facultad de Ciencias de la Información, Universidad Complutense de Madrid, durante cuatro horas y en el curso académico 2013/2014. 
Elegimos esta metodología de investigación porque consideramos que era verdaderamente necesaria una investigación cualitativa. El análisis cuantitativo, a través de encuestas y tests, no hubiera sido suficiente porque las y los periodistas no cuentan con tiempo suficiente para responder en profundidad a esas cuestiones; porque las encuestas son una herramienta muy fría e incompleta para responder a cuestiones vitales y que implican distintos niveles de análisis y complejidad dada la escasa formación en género en la formación de profesionales de la comunicación; porque algunas personas preferían un entorno de confianza y confidencialidad para sus respuestas, propuestas y planteamientos; porque les resultó positivo que les convocásemos a una cita donde hubiera más colegas de profesión con quienes debatir sobre cuestiones que suelen generar muchas dudas; y porque gracias a todo lo anterior, creábamos el mejor clima de complicidad y confianza para hablar, expresando opiniones, dudas, incertidumbres y desconocimiento, en ocasiones, sobre las políticas de género reales en los medios de comunicación españoles y sobre la igualdad entre mujeres y hombres en la formación de la profesión periodística.

Acudieron periodistas de radio, prensa, televisión y agencias de noticias, todos de nivel nacional, y de titularidad pública y privada. No podemos incluir un listado del medio y del nombre y apellidos del profesional que representaba a cada medio, porque incumpliríamos la confidencialidad. Podemos indicar que los principales medios españoles estuvieron representados. Fueron seleccionados escribiendo a la Dirección de cada medio, pidiendo el contacto de la persona que se dedicara a temas de género o que estuviese interesada en la materia o por contacto de otras y otros profesionales del periodismo. La encargada de realizar los contactos fue la periodista e investigadora Marta Solano, que se encargó, además, de moderar la mesa de trabajo. No hubo selección, ni se cerró el acceso absolutamente a nadie. Se les citó por email y por teléfono y se cerró el encuentro para una reunión que duró alrededor de 4 horas, como señalamos anteriormente, en la Sala de Profesores de la Facultad de Ciencias de la Información, presidido por la Decana de la Facultad, Carmen Pérez de Armiñán.

\section{DISCUSIÓN}

\subsection{MARCO TEÓRICO}

El triunfo de las revoluciones liberales no significó un espacio de libertad para las mujeres. Ellas participaron activamente de la revolución, con la voz y con la palabra, escribiendo y difundiendo las ideas del cambio. También lo hicieron con las armas y sus nombres ocupan un lugar en la historia. Aunque esos nombres no tienen espacio en los libros de texto, ni de las escuelas ni de las Universidades, y se han ido olvidando. Ellas fueron publicistas de la revolución y periodistas, heroínas de renombre y también mujeres anónimas comprometidas con las libertad. Sin embargo, cuando se abrieron los debates para construir un nuevo modelo político, social y económico, ellas fueron marginadas, se las privó de derechos políticos y también del acceso a la 
educación, se las relegó al ámbito de lo privado y se les negaron derechos de ciudadanía.

Recordemos la Declaración de Derechos del Hombre y del Ciudadano de 1789, un texto que abre una profunda reflexión sobre la desigualdad entre hombres y mujeres dado que ellas no fueron incorporadas a los "Derechos". Se inspiró en la Declaración de la Independencia de los Estados Unidos de 1776. Su preámbulo manifiesta que la Asamblea Nacional se ha reunido para crear una "declaración solemne" que exponga "los derechos naturales, inalienables y sagrados del hombre". Algunos de sus artículos resultan muy importantes desde nuestra posición de profesionales de los medios de comunicación. Así, el artículo 11 cita la libre comunicación de pensamientos y de opiniones y lo califica como "uno de los derechos más preciosos del hombre". Este derecho permite a todo ciudadano "hablar, escribir e imprimir libremente, a trueque de responder del abuso de esta libertad en los casos determinados por la ley".

Estas libertades suponían grandes avances y supuestamente, para todos (los hombres), pero excluyeron a las mujeres, traicionadas en los primeros años de la revolución. Olympe de Gouges sería condenada y guillotinada por ejercer su derecho a la libertad de expresión. Dos años después de la Declaración de Derechos del Hombre y del Ciudadano, denunció el texto anterior porque no incluía a las mujeres. La Declaración sólo hablaba de "hombre", "hombres", "ciudadano" y "ciudadanos". La activista revolucionaria, política, pensadora y escritora redactó un nuevo texto. Este acto y su enfrentamiento con Robespierre y Marat la llevarían a la muerte, por escribir una carta pública contra el primero (Pronostic de Monsieur Robespierre pour un animal amphibie).

Reivindicaba a las mujeres que quedaron olvidadas en la Declaración Universal de los Derechos del Hombre y del Ciudadano. La estructura de su texto, que incluye a Hombres y Mujeres, es muy similar al primer texto, porque reproduce los mismos artículos introduciendo los cambios necesarios para poner de manifiesto la realidad de las mujeres y sus especiales circunstancias. Por ejemplo, el artículo 4, que hablaba de libertad, expone que los derechos de las mujeres han estado limitados por la tiranía perpetua del hombre. El artículo 10, que hablaba de las opiniones, incluye una idea importantísima: el derecho de la mujer a hablar en público, al igual que puede subir al cadalso. Este derecho permite sacar a las mujeres del ámbito privado, al que han sido relegadas. Por último, el artículo 11 reivindica la libertad de pensamiento y opinión como "uno de los derechos más valiosos de la mujer".

Estas ideas no serían concretadas en políticas y regulaciones hasta el siglo XX, aunque muchas mujeres siguieran luchando en diferentes lugares del mundo por sus derechos, que son derechos humanos, y fuesen por ello reprimidas, encarceladas, asesinadas y condenadas al exilio o a la marginación. La lucha por el sufragio será una de las más extensas y amargas, pues hasta "sufragio universal" se llamó inicialmente a lo que era "sufragio masculino" y se crearon 
partidos y modelos llamados "demócratas" que excluían a las mujeres. Las mujeres irán consiguiendo su derecho al voto muy lentamente, a lo largo del siglo XX, y sin derechos políticos, no tuvieron acceso a otros derechos.

Las Naciones Unidas (ONU), en 1946, dieron un paso adelante con la Comisión sobre la Condición Jurídica y Social de la Mujer. Creó un borrador que pretendía ser instrumento legal para articular los derechos de hombres y mujeres. Según indica García-Berrio Hernández (2008: 146), sus años de mayor actividad fueron los comprendidos entre 1975 y 1985, con las tres primeras Conferencias Mundiales de las Naciones Unidas sobre la mujer. Antes de llegar a esas conferencias centradas en la mujer, hay que repasar otros momentos importantes para el avance de los derechos de las mujeres.

El primero de ellos tiene lugar en 1950, cuando Naciones Unidas cambia su Declaración Universal de los Derechos del Hombre por Declaración Universal de los Derechos Humanos. Más adelante, en 1979, la Asamblea General crea la Convención para la eliminación de todas las formas de discriminación contra la mujer (CEDAW). En 1980, tiene lugar la Conferencia Mundial del Decenio de las Naciones Unidas para la Mujer, en Copenhague (Dinamarca).

El siguiente paso, y de gran importancia, será en 1993 con la Conferencia Mundial de Derechos Humanos, celebrada en Viena entre el 14 y el 25 de junio de 1993, para reafirmar y renovar los principios de la Declaración Universal de Derechos Humanos de 1950. Este texto incluye, en su artículo 18, lo que más nos interesa para cumplir los objetivos propuestos en esta investigación: "Los derechos humanos de la mujer y de la niña son parte inalienable, integrante e indivisible de los derechos humanos universales. La plena participación, en condiciones de igualdad, de la mujer en la vida política, civil, económica, social y cultural en los planos nacional, regional e internacional y la erradicación de todas las formas de discriminación basadas en el sexo son objetivos prioritarios de la comunidad internacional".

En el contexto internacional, otro hito importante es la Cuarta Conferencia Mundial sobre la Mujer de las Naciones Unidas, celebrada en Beijing (o Pekín, China), del 4 al 15 de septiembre de 1995. Allí acudieron más de 180 delegaciones gubernamentales y 2.500 organizaciones no gubernamentales. Era la primera vez que los derechos humanos de las mujeres se trataban a escala mundial, para conseguir resultados positivos en los cinco continentes. Previamente, se habían celebrado conferencias similares en México (1976), la ya citada en Copenhague (1980) y otra en Nairobi (1985). Sin embargo, la de Beijing se considera la de mayor magnitud e importancia. A través de 12 puntos o "esferas de preocupación", se identificaron todos los obstáculos de las mujeres "para vivir en igualdad, desarrollo y paz". Entre esos puntos, encontramos, precisamente: "La movilización insuficiente de los medios de información para promover la contribución de la mujer a la sociedad".

La Conferencia de Beijing tiene, además, otra serie de puntos que nos interesan 
porque se centran en los medios de comunicación. Se trata de aquellos contenidos en el Capítulo J, que versa sobre "La mujer y los medios de difusión". Según éste, los avances tecnológicos han facilitado la comunicación mundial, eliminando fronteras e influyendo en adultos y jóvenes. Sin embargo, muchas veces, los medios difunden imágenes negativas de la mujer, 0 productos pornográficos y degradantes que deberían ser perseguidos y eliminados a través de la autorregulación. No se centra sólo en los medios más innovadores, ya que dedica mucha importancia a todos los medios tradicionales de difusión, nacionales e internacionales. Estos deben defender la libertad de expresión y la imagen equilibrada de hombres y mujeres. El objetivo es eliminar estereotipos sexistas, pornografía y escenas de violencia.

El año 1999 marca un gran avance en la toma de conciencia de la violencia de género, cuando la Asamblea General de la ONU declaró como Día Internacional para la Eliminación de la Violencia Contra las Mujeres el 25 de noviembre. Gil Ambrona (2008: 511) explica que se eligió ese día en memoria de las hermanas Patria, Minerva y María Teresa Mirabal Reyes, asesinadas por agentes del Servicio Militar de Inteligencia del dictador dominicano, Leónidas Trujillo. El objetivo era invitar a todos los gobiernos e instituciones a organizar, en esa fecha, cada año, actividades contra la violencia sexista, incluida la violencia en los medios de comunicación.

\subsection{Políticas de género sobre medios de comunicación en España}

Después de conocer los precedentes internacionales más relevantes, es necesario centrarse en el estado de la cuestión en España, para responder al interrogante propuesto en las primeras líneas: ¿Cómo ha sintentizado la regulación española esas directivas o consejos en cuanto a medios y género? Podemos indicar que lo ha hecho con dos Leyes Orgánicas: Ley Orgánica 1/2004, de 28 de diciembre, de Medidas de Protección Integral contra la Violencia de Género y Ley Orgánica 3/2007, de 22 de marzo, para la igualdad efectiva y mujeres y hombre. Para analizarlas, no describiremos todos los elementos de cada ley. Sólo nos centraremos en los temas modulares que traten las políticas de género sobre medios de comunicación.

La Ley de Medidas de Protección Integral contra la Violencia de Género expone, con firmeza, que la violencia de género no es un problema del ámbito privado y que se trata del símbolo más brutal de desigualdad de la sociedad actual. Cita el artículo 15 de la Constitución Española, que defiende el derecho a la vida y a la integridad física y moral, y la Conferencia de Beijing de 1995. Ahí tenemos la primera aportación de las políticas internacionales de la ONU, estudiadas en el punto anterior, pero también las reivindicaciones históricas del movimiento feminista de las que se hacen eco las políticas internacionales y las nacionales.

La Ley deja constancia de que los poderes públicos deben emprender acciones para defender y hacer reales los derechos inalienables. Martínez García (2008, p. 24) explica que esta Ley tiene un valor indiscutible por su carácter 
transdisciplinar y su búsqueda de la prevención como medio de transformación social. Su objetivo más importante es evitar que la mujer llegue a ser víctima; la solución está en la prevención.

Los medios de comunicación tienen, en esa prevención, una importante e ineludible tarea. El Capítulo II se refiere a la publicidad y a los medios de comunicación. El artículo 10 habla de la publicidad ilícita y expone que, de acuerdo con lo establecido en la Ley 34/1988, de 11 de noviembre, General de Publicidad, se considerará ilícita la publicidad que utilice la imagen de la mujer con carácter vejatorio o discriminatorio. El artículo 11 asegura que el Ente público velará para que los medios audiovisuales traten a la mujer de acuerdo con los principios y valores constitucionales. Por su parte, el artículo 13 expone que se erradicarán las conductas favorecedoras de la desigualdad de las mujeres en los medios de comunicación. Se favorecerán acuerdos de autorregulación y mecanismos de control preventivo. Los medios tratarán las informaciones relacionadas con la violencia de género con objetividad y defendiendo los derechos humanos, la libertad y la dignidad. Concreta que "se tendrá especial cuidado en el tratamiento gráfico de las informaciones".

El Título III contiene otras ideas fundamentales, que han de ser conocidas por los profesionales de los medios de comunicación. De hecho, el artículo 29 cita la Delegación Especial del Gobierno contra la Violencia sobre la Mujer, adscrito al Ministerio de Trabajo y Asuntos Sociales, en el momento de redacción de la ley. El siguiente artículo versa sobre la creación del Observatorio Estatal de Violencia sobre la Mujer, adscrito al mismo ministerio. Éste asesorará, evaluará y elaborará informes, estudios y propuestas de actuación en materia de violencia de género; y remitirá un informe anual sobre violencia de género, al Gobierno y a las Comunidades Autónomas.

Por otro lado, la Ley Orgánica 3/2007, de 22 de marzo, para la igualdad efectiva y mujeres y hombre también cita la Convención sobre la eliminación de todas las formas de discriminación contra la mujer, aprobada por la Asamblea General de Naciones Unidas en diciembre de 1979, las conferencias de Nairobi (1985) y Beijing (1995), y el Tratado de Ámsterdam de 1999. Nos interesa citar su Título III, que establece medidas en materia de igualdad y medios de comunicación. Los medios de titularidad pública transmitirán "una imagen igualitaria, plural y no estereotipada de mujeres y hombres en la sociedad, y promoverán el conocimiento y la difusión del principio de igualdad entre mujeres y hombres". Concretamente, la Corporación RTVE reflejará la presencia de las mujeres en los diversos ámbitos de la vida social, utilizará un lenguaje no sexista, y adoptará códigos de autorregulación que transmitan el principio de igualdad. Estas mismas medidas son aplicadas para la Agencia EFE. Por otro lado, los medios de titularidad privada evitarán cualquier discriminación y promoverán acuerdos de autorregulación para el cumplimiento de la ley.

Tras el análisis de estas dos leyes, nos preguntaremos: ¿periodistas y profesionales de la comunicación las conocen, las aplican, detectan errores o 
exigen más legislación y formación al respecto? Respondemos a esta cuestión en el siguiente apartado, tras haber detallado algunos puntos de las dos principales leyes españolas, pioneras respecto al resto del mundo, inspiración para otros países miembro de la Unión Europea y de otros lugares, vertebradora de otra legislación actual que aborda políticas de género en los medios de comunicación, de forma más o menos profunda.

\subsection{Resultados de la investigación con el grupo focal}

En las líneas siguientes, como comentábamos al inicio del artículo, explicamos las declaraciones de las y los periodistas y personas vinculadas al ámbito de la comunicación con las que se mantuvo un debate en el focus group o grupo focal. El encuentro con profesionales tuvo lugar en la Facultad de Ciencias de la Información, Universidad Complutense de Madrid, durante cuatro horas y en el curso académico 2013/2014. Fue moderado por la periodista de TVE, Marta Solano, dirigido por las autoras de este artículo, con la colaboración de la Decana de la Facultad de Ciencias de la Información, María del Carmen Pérez de Armiñán García-Fresca.

El acto fue a puerta cerrada, sin asistencia de estudiantes, porque el objetivo era valorar el conocimiento de la legislación en materia de igualdad, por parte de quienes deben informar sobre igualdad y sobre violencia, así como su formación en materia de igualdad y su comprensión de conceptos y términos de género. Por otro lado, se tuvo en cuenta el conocimiento y utilización de un lenguaje no sexista e inclusivo. En el apartado del Marco Metodológico, repasamos todos los criterios y los motivos de elegir la metodología de investigación de grupo focal, y la invitación a esos medios y a sus profesionales. Como expresábamos en los interrogantes preliminares, el objetivo era descubrir si periodistas y profesionales de la comunicación en España conocen las políticas de género vinculadas a los medios de comunicación, y si comprenden su necesidad y significado.

Las invitadas y los invitados relataron así sus experiencias, la línea editorial de su medio o el lenguaje sexista o no inclusivo, que usan por desconocimiento unas veces, o porque se ven en la obligación de utilizarlo en otras ocasiones. A lo largo de la conversación y el debate, las y los asistentes plantearon que no siempre actúan adecuadamente al informar y que, en ciertas ocasiones, es porque no tienen formación en género. Toda su formación académica ha ignorado las cuestiones de género. Para evitarlo, proponen nuevas líneas de regulación ética y deontológica en materia de género y una mayor formación teórica en género y feminismo (el término "feminismo" es el más desconocido y mal utilizado) que permita un marco teórico desde el que enfocar la información sobre temas de igualdad y violencia de género.

Hemos dividido la larga conversación por bloques temáticos para facilitar la comprensión. Estos ejes temáticos responden a los títulos y citas escogidas de las políticas analizadas en el marco teórico, y a las dos leyes de igualdad 
españolas sobre las que hemos reflexionado. Así, van de lo general a lo concreto; de las políticas públicas al trabajo real y diario de las y los profesionales de la comunicación; y en el mismo orden temporal en el que surgieron en la reunión, donde la confianza y complicidad llevaron a respuestas más concretas y profundas. Los temas que se abordaron más en profundidad fueron los que a continuación se exponen, intentando mantener las opiniones y reflexiones en el mismo tono en que fueron expresadas y planteadas.

\subsection{De la comprensión de las diferencias entre sexo y género, a comprender que informar sobre la violencia contra las mujeres no es introducir la igualdad en los medios de comunicación.}

Se crea una cierta confusión. Algunas/os profesionales no se habían planteado antes la distinción entre "sexo" y "género", ni tampoco la diferencia entre informar sobre "igualdad" o informar sobre "violencia de género o violencia machista". De hecho, se vincula informar sobre igualdad con informar sobre violencia de género, sin comprender el concepto "género" en algunas ocasiones.

Profesionales que no tenían previa formación en género creen estar informando sobre igualdad cuando informan sobre violencia machista. A partir de ahí, se plantean los efectos que pudo tener la utilización del concepto "crimen pasional" para referirse a los asesinatos machistas. Es una cuestión de formación, de saber, pero no todas las personas que se dedican al periodismo tienen esa formación y todas han sido socializadas (como el resto de la población) desde la no igualdad entre mujeres y hombres y la naturalización de esa desigualdad (lo que no se ve y no se sabe no se puede transmitir, porque no existe).

El uso de "colectivo" para referirse a las mujeres se usa habitualmente en los medios. Pero no se puede tratar a las mujeres como un colectivo porque son más del 50 por ciento de la sociedad. Más de la mitad de la población tiene derechos a los que se no se da visibilidad habitualmente. Los derechos humanos no pueden ocupar las páginas de sociedad, sin embargo los temas relacionados con "igualdad" o con "violencia" se introducen en secciones de "sociedad". Las desigualdades son una cuestión política y deben ocupar páginas de política nacional e internacional, por su parte la violencia machista debe tratarse como una cuestión que afecta a la democracia. Ninguna sociedad democrática puede permitir que las mujeres sean asesinadas por el hecho de ser mujeres, y hay más mujeres asesinadas en España en la actual democracia por machismo que por terrorismo político hombres y mujeres. Una reflexión que no siempre se hace. En ello los medios tienen una gran responsabilidad.

Esta cuestión abre un debate a partir de una reflexión sobre la violencia y sobre cómo se "mira" y se "ve" la violencia machista, los estereotipos, roles y valores naturalizados. El concepto "género" como construcción social y cultural debe ser transmitido y para ello es preciso formar a profesionales de la comunicación 
desde una perspectiva de género. Lo relacionado con las mujeres, tal vez porque se vinculó históricamente con lo privado, se ha visto como algo de carácter "social" y particular, no político. La violencia de género es un delito contra los Derechos Humanos. Los derechos de las mujeres son derechos humanos y en ese contexto, deben ser analizados y explicados.

Aunque no suelen vincularse en los medios de comunicación ambos derechos; ni siquiera se analizan las causas de esa violencia que es preciso explicar desde un marco teórico feminista, porque no se puede continuar informando sobre violencia contra las mujeres, sin explicar que ésta no tiene que ver con cuestiones aisladas, con casos concretos y personales, ni se da en entornos de población marginal, sino porque existe una violencia estructural. Las invitadas y los invitados tienen muy diferente formación en materia de igualdad, y también diferentes sensibilidades, ideologías, edades. Esto fomenta un debate que pone de manifiesto, una vez más, la necesidad de formar desde conceptos muy básicos, porque de otra manera, los protocolos de actuación o las Guías de Buenas Prácticas no tendrán los efectos deseados.

Se explica el caso de una jueza asesinada por su marido, con un eco mediático diferente al de los demás asesinatos por violencia machista. Una mujer asesinada de nivel económico y cultural elevado no tiene el mismo tratamiento informativo que una mujer analfabeta, asesinada en un pequeño pueblo. Existe otro caso similar, el de una joven argentina asesinada en España. Sus compañeros acudieron a los medios de comunicación para decir que no era inmigrante ilegal, sino una doctoranda universitaria que había viajado a España para terminar y defender su tesis. Estaban indignados por el tratamiento que su amiga y compañera recibía en los medios de comunicación tras ser asesinada por violencia machista.

Es imprescindible que desde la información periodística se expliquen las causas profundas y reales de esa violencia desde la transversalidad. Se plantea, en un momento dado, que la política lo "asfixia todo" y por eso, no hay espacio, ni tiempo para profundizar en cuestiones de "igualdad". En ese momento del debate, se plantea que hay que redefinir el concepto de "política". Las políticas de igualdad y el valor de la igualdad deberían formar parte de las secciones consideradas de "mayor valor": nacional e internacional, economía y, por supuesto, opinión. La igualdad entre mujeres y hombres, que hay que separar de la violencia machista, es transversal en la política y en la economía, y tiene fuertes implicaciones en las transformaciones sociales.

\subsection{Visibilidad de las noticias sobre violencia machista}

Varias personas asistentes coinciden en que hay un antes y un después de la muerte de Ana Orantes en la información sobre violencia para el ámbito periodístico. La violencia empezó a tener visibilidad en los medios y, por tanto, en la sociedad española, y las/los periodistas tomaron conciencia de esa realidad y de su gravedad. Las políticas encaminadas a hacer visible la violencia 
machista han sido eficaces y sirven de ejemplo a otros países, porque la violencia ha salido de lo privado.

Indican que hay violencia en temas que no se tratan y no hay que tratar la violencia de género al margen de otros tipos de violencia, aunque es preciso explicar claramente las causas de esa violencia. Hay que poner de manifiesto las causas de la desigualdad entre mujeres y hombres en España y en el mundo. Esa formación no se da en las Universidades, ni siquiera se explica en las clases de Historia todo el proceso de segregación de las mujeres en los espacios políticos tras las revoluciones liberales, ni su posición legal como mujeres en distintos momentos históricos. Se habla de la Declaración de Derechos del Hombre y del Ciudadano, sin especificar que las mujeres quedaban fuera de los derechos, ni siquiera nadie se plantea esa cuestión.

Donde hay desigualdades, acaba habiendo violencia. Por eso, lo primero es luchar por la igualdad entre mujeres y hombres en todos los ámbitos. Hay protocolos establecidos por las dos leyes españolas en materia de igualdad, para informar sobre casos de violencia de género, pero no hay formación para detectar desigualdad, o para difundir contenidos encaminados a que la sociedad tome conciencia de la posición de mujeres y de hombres en el ámbito laboral, de las trabas sutiles, de la discriminación indirecta, de la necesidad de incorporar acciones positivas, rompiendo además con los estereotipos de mujeres y de mujeres, de roles y de prejuicios.

Las periodistas más expertas en temas de género argumentan que no hay que desligar nunca violencia y desigualdad. Toda la información debe tener una perspectiva de género y sobre todo, de igualdad. Y se debería enseñar en las Facultades de Ciencias de la Información y/o de Comunicación, según manifiestan las personas asistentes que provienen del ámbito académico. Además, no hay que diferenciar entre temas blandos y temas duros, algo que se hace habitualmente en los medios de comunicación, o entre temas de hombres y temas de mujeres. La igualdad es un asunto que importa a todos y todas. Son temas que deben interesar, e interesan, si se explican adecuadamente.

\subsection{Atención especial al lenguaje, porque sólo lo que se nombra existe}

El uso de un lenguaje inclusivo es fundamental para dar visibilidad a las mujeres en la sociedad española. En esto no están de acuerdo todas las personas asistentes. La educación ha tenido mucha fuerza y "lo que no se nombra no existe". Por ello, hay que nombrar a las mujeres, utilizar el femenino para que las mujeres que no se nombraron, ocupen un lugar en los espacios públicos. No es un problema menor y el masculino no incluye a las mujeres, por mucho que se hable del "genérico". El tema abre un debate muy intenso.

Un sector recomienda forzar el femenino inclusivo y que se pueda decir "El rey 
ha tenido su octava nieta", en lugar de "El rey ha tenido su octavo nieto, que ha sido una niña". Alguna asistente reconoce que hacer una diferenciación por sexo y decir siempre "señores y señoras" es imposible, pero bastaría con usar palabras que incluyen, por ejemplo: en lugar de ciudadanas y ciudadanos, se puede decir "ciudadanía". Aunque en ocasiones, es preciso poner en valor el femenino para visibilizar la incorporación de las mujeres al ámbito público.

Por su parte, una periodista muy experta en género, exhorta a revisar expresiones antiguas, que damos por buenas pero que son erróneas, como "sufragio universal masculino". Este tema se mantiene todavía en muchos libros de Historia y el sufragio universal sólo puede ser sufragio universal: incluyendo a toda la ciudadanía que está compuesta por mujeres y por hombres.

Otro periodista dice que no sólo hay error por sexismo, sino error por no saber de Historia. En el aniversario de "La Pepa", pocos medios de comunicación dijeron que la Constitución permitía, por primera vez, votar a todos los hombres, independientemente de sus rentas, pero no permitía votar a las mujeres por mucha renta que tuviesen. Son datos que hay que dejar claros, que hay que difundir, porque además en el periodismo, y en otros ámbitos, se usa "hombre" con excesiva frecuencia como "especie humana". Esto atenta claramente contra el principio de igualdad, ya que es un término que fue utilizado en la época contemporánea, precisamente porque el "hombre" era el ciudadano y el que tenía derechos, derechos que no tenía resto de la población no ciudadana, independientemente de que ellas no cesasen en sus reivindicaciones.

La Academia de la Lengua también es misógina y sexista en algunas de sus decisiones, y beligerante contra el uso del lenguaje femenino, señalan algunas periodistas. Es un problema de poder y la Academia debe incorporar a las mujeres porque suponen, al menos, la mitad de sus hablantes. El problema del lenguaje también viene de la propia Academia porque el lenguaje nombra y hay incongruencias. Además, los medios de comunicación cuentan con decálogos, escritos y sin escribir, que no se incorporan a los libros de estilo o se tratan con "cansancio".

Otras opiniones se centran en que el problema no está tanto en el uso del lenguaje, sino en el tratamiento de la información. Recuerda alguien el titular "Mi papá mató a mi mamá" y muchísimas noticias que dan nombre y apellidos, la calle y el pueblo o la ciudad donde ocurren los hechos. Esas informaciones son sensacionalistas y tienen sangre en cada línea, aunque no empleen un lenguaje puramente sexista, ahondando en la idea de que la violencia no está en la pura lingüística. No es grave el lenguaje, sino lo que subyace bajo el lenguaje. Alguien pone como ejemplo a la presidenta argentina, conocida mundialmente como Cristina de Kirchner, cuando se llama Cristina Fernández.

\subsection{Violencia en la información}


Se explica que el tratamiento sensacionalista de las noticias violentas está en contra de todos los decálogos, por ejemplo, de RTVE. Sus trabajadores y trabajadoras intentan escapar de frases hechas y tópicos que no añaden nada sobre los hechos, sino que nos alejan de ellos. En RTVE no usan los domicilios, nombres, manchas de sangre, ni imágenes de cadáveres bajo la manta térmica amarilla. Sin embargo, hay informativos que sólo se centran en la sangre. TVE no lo hace, pero el resto de cadenas sólo lanzan telediarios con una alta concatenación de noticias de sucesos. Hay quien dice que hay que contarlo todo y no dejar detalles por miedo a que provoquen un efecto de imitación. También, quien afirma que las noticias se atienden con demasiada urgencia y esto impide contrastar los datos, informantes, etc. El periodismo no profundiza en los detalles y si lo hace, no importa porque al día siguiente, nadie pregunta y han pasado a otra cosa.

Los medios de comunicación tienden demasiado al espectáculo y a la estadística y hay que huir del infoespectáculo. Hay que evitar la saturación de información por exceso de noticias y dar pocas noticias, pero bien analizadas. Igualmente, hay un problema al abordar la violencia de género. Tratan tantas noticias y tan parecidas, que ya no saben qué vueltas darles para llegar al espectador. Se esfuerzan por buscar nuevos enfoques, por tratarlas de otra forma. Hay que buscar nuevos enfoques y nuevos reportajes. Además, hay que tratar la información desde otros ámbitos que nunca, o pocas veces, se tratan: los huérfanos, los juicios, las condenas... Alguien pone el ejemplo de Afganistán, porque ningún medio ha vuelto a hablar de sus mujeres después de que acabara la guerra. Ya no tienen visibilidad.

\subsection{Estereotipos sobre las mujeres}

Los medios de comunicación han construido modelos de mujeres muy estereotipados: el objeto sexual, la mujer rebelde o mayor, el "fenómeno de la naturaleza", que triunfa en el trabajo y en el hogar, y las víctimas (que son las que mayor espacio ocupan en la información periodística). Se añade que junto con los estereotipos femeninos, se han también creado estereotipos masculinos, que deben ser igualmente eliminados. Además, asociamos la belleza masculina a un concepto concreto de masculinidad y esto es otra forma de estereotipar y de acabar con la anhelada igualdad.

Los estereotipos y los modelos los observamos en el ámbito periodístico, tanto en la información que se transmite como en la propia profesión. Por ejemplo, el periodismo deportivo tiene unas características muy especiales. Algunos periodistas deportivos que acuden al encuentro huyen de una posición beligerante y admiten, a priori, que todo lo que se diga de sexismo en periodismo deportivo, seguramente, será verdad. Es un problema estructural y las mujeres que llegan a su primer trabajo, traen ese machismo incorporado. En deporte, el sexismo vende y sólo hay que ver la famosa fotografía de la contraportada del diario As. Existe desde 1967, cuando sacaron una foto de Concha Velasco. Más adelante, se cambió por una foto de una chica periodista 
que escribía y tuvieron que volver a cambiarla. Saben que eso es lo que más se visita en su página Web. Hay, además, mujeres periodistas atractivas en deportes porque, lamentablemente, los futbolistas se paran a hablar con ellas y no con ellos.

Por otro lado, no se les da buena cobertura a las mujeres deportistas. Nadie sabe decir más de dos nombres de mujeres que se dediquen profesionalmente a un deporte. Esto ocurre porque no salen en los medios o porque cuando salen, no se las trata con la normalidad que debiera, ni se las impulsa, ni se genera interés. María de Villota, piloto de Fórmula 1 en la temporada 2012, es el mejor ejemplo. Ni siquiera en España la conocimos como se mereció, hasta su trágico accidente y posterior fallecimiento. Las mujeres sólo aparecen en portadas cuando ganan alguna medalla en los Juegos Olímpicos, y se olvidan rápidamente. Además, los periodistas españoles tienen un peligroso carácter latino. En los medios anglosajones, por ejemplo, no existe ese sexismo en el periodismo deportivo y se respeta a las mujeres periodistas y a las profesionales del deporte. Esta reflexión bien merece posteriores estudios e investigaciones.

Por otro lado, algunos asistentes afirman que hay un sustrato machista y una desigualdad manifiesta entre periodistas y estudiantes de Periodismo. Estamos en los albores de la igualdad porque cualquier análisis o comentario, en cualquier medio, al final se deja arrastrar. La lucha por la igualdad no ha acabado, sino que está en el corazón mismo de la sociedad y empezará a triunfar cuando sea también lucha de los varones.

Se propone una formación y sensibilización permanente de las/los periodistas y un esfuerzo por eliminar las agendas que son de hombres. Generalmente, cuando se buscan personas expertas para opinar sobre determinados temas en los medios de comunicación, se tiende a buscar "hombres". Por ejemplo, se pregunta a economistas varones cuando hay multitud de economistas mujeres (porque hay temas que se identifican con lo "masculino" o con lo "femenino") y ahí sí es necesario recuperar ciertas cuotas de paridad para conseguir la igualdad, en la opinión de las mujeres, en los referentes de valor de las mujeres. La única directora de un medio español (en el momento en que se realiza el Encuentro) es Montserrat Domínguez, que preparaba entonces la versión nacional de The Huffington Post. Ella es la única mujer que tiene una clara posición de poder en los medios españoles. Esto debe abrir muchas reflexiones sobre el concepto de poder y sobre cómo se transmite la información. En cambio, en RTVE casi todas las profesionales son mujeres, especialmente en la Dirección de Informativos.

Las periodistas recién licenciadas son las primeras que tienen que luchar contra esa situación. No ayuda que envíen su primer currículum vitae con sus medidas corporales, como comenta alguien en la sala, esperando ganar un trabajo por su apariencia física; lo que dice mucho del funcionamiento de los "imaginarios" femeninos y masculinos. Muchas mujeres son conscientes de la desigualdad, 
pero no denuncian: las mujeres se preguntan: "¿si denuncio, me quedo en el paro?". Hay que tratar el tema del empleador y pensar qué ocurre en "nuestro trabajo", afirma una participante.

\subsection{Posiciones ante la prostitución: los ingresos económicos de los anuncios de "contactos"}

Los medios de comunicación pueden mostrarse "muy dignos" en apariencia y hacer manuales de estilo que incorporen cuestiones de género, prometiendo, además, un tratamiento más justo de la realidad de las mujeres. Pero son muchos los periódicos que siguen incluyendo en sus páginas los mal llamados "anuncios de contactos", que son anuncios de prostitución por los que obtienen grandes ingresos. "No se cree nadie, así, la igualdad". Es imposible decirle a un gerente de un periódico que prescinda del dinero de esos anuncios, aunque es el primer paso que deberían dar, si respetan el principio de igualdad y la legislación vigente en materia de igualdad y lucha contra la violencia de género. El diario Público fue pionero en España y ha acabado en una situación ruinosa, que le ha llevado a retirar su edición en papel, destacan muchas y muchos de los asistentes. Ese es un tema que daría para más debate, pero en el que no se termina profundizando.

\subsection{Educación en todos los niveles de la enseñanza}

Deberían existir asignaturas e iniciativas en todos los niveles de educación. Así, se creará una sociedad crítica, que analizará la información desde una perspectiva diferente y no tolerará informaciones que atenten contra los derechos de las mujeres. La base de la sociedad es machista y se ha de educar a niñas y a niños con nuevos referentes, poniendo fin a estereotipos dañinos, que favorecen la violencia de género: especialmente, el mito del amor romántico. Muchas/muchos asistentes defienden el valor de la asignatura "Educación para la ciudadanía".

Es preciso formar a periodistas con perspectiva de género y con amplia cultura. Aunque cuando estudian en las Universidades, la mayoría no entienda el valor de asignaturas no específicamente vinculadas a la práctica del periodismo, a largo plazo esas materias son fundamentales en la formación de futuras y futuros profesionales. Las/los periodista deben ser capaces de relacionar política, economía, deporte, arte, literatura, cultura en general, e incorporar la ética transversalmente. La súper especialización no debe ser un objetivo porque actualmente, ser interdisciplinar te asegura un trabajo. Hay que amueblar cabezas como paso previo a conseguir la igualdad, afirman muchas y muchos profesionales.

Alguna periodista plantea la necesidad de que se eduque para que se detecten las desigualdades de género en la formación de profesionales en las universidades, desde las materias que se imparten al discurso del profesorado. Hay quien plantea al Rector la necesidad de crear un Observatorio en la 
Facultad de CC. de la Información en materia de género. El/la periodista debe salir de la Universidad con una especialización en género que le permite abordar transversalmente diferentes temas. La violencia machista no es un tema menor, ni poco prioritario, como se señala en diversas ocasiones. Lamentablemente, se asocia a temas sociales de segunda división, también en la formación universitaria. Hay que formar en igualdad de género. Avanzaremos cuando se trate como asunto político y forme parte de la educación es el primer paso para introducirlo en las secciones de "Política".

\section{CONCLUSIONES Y CONSIDERACIONES}

El periodismo fue, en sus inicios, un medio para reivindicar transformaciones sociales, políticas y económicas, utilizado por quienes participaron en las revoluciones liberales como medio de expresión de sus ideas. Las mujeres también participaron activamente en la revolución y el periodismo fue una de sus armas, utilizaron los llamados papeles periódicos para difundir sus ideas y pensamientos, y fueron luego reprimidas en los momentos de reacción, teniendo que partir al exilio o sufriendo condenas. .

Las mujeres fueron, además, doblemente reprimidas por defender su derecho a la participación política y a la ciudadanía. Y fueron reprimidas por los opositores de la revolución y por aquellos con quienes habían luchado por cambiar un sistema político y económico. Muchas más fueron condenadas, marginadas, segregadas o enviadas al exilio, pero no ocupan el espacio que merecen en los libros que se estudian en las Facultades de Periodismo y/o Comunicación, lo cual impide que existan referentes para la formación de profesionales de la comunicación con perspectiva de género.

La prensa, y otros medios de comunicación también fueron garantes del sistema patriarcal establecido, que atribuía a las mujeres un lugar concreto en la sociedad, relegándolas al espacio privado. Combatirán ardientemente contra las sufragistas, y contra el movimiento feminista, contra aquellas que exigen derechos y leyes que las protejan contra las desigualdades. Pero las mujeres sabrán también ocupar un espacio en el periodismo y utilizarlo para poner de relieve la desigualdad y la necesidad de un cambio, al tiempo que difunden los avances que se producen a nivel internacional y nacional. Ellas serán también periodistas y dirigirán revistas y periódicos reivindicativos, revolucionarios e innovadores, con dificultad pero sin cesar en su empeño, mientras van ganando espacios en la prensa tradicional y en los grandes medios de comunicación a lo largo del siglo XIX y del XX.

El siglo XXI se inaugura con grandes cambios, fruto de las reivindicaciones del movimiento feminista a lo largo de dos siglos y de los logros conseguidos con sus luchas. España, siguiendo las líneas marcadas por los organismos internacionales en esta materia, introduce cambios fundamentales a partir de 2004 con la Ley Orgánica de Medidas de protección integral contra la violencia de género, una ley que marca un antes y un después en la lucha contra la 
violencia de género y que implica a diferentes agentes en la prevención, entre ellos los medios de comunicación. La Ley para la Igualdad efectiva de mujeres y hombres, en 2007, supone también un salto adelante introduciendo medidas para que la igualdad se incorpore a diferentes ámbitos y para trabajar en la sensibilización y en transformaciones fundamentales. No obstante, las leyes no lo cambian todo. Es preciso formar en igualdad, explicar las causas de la desigualdad para que se comprenda, en su totalidad, que bajo la apariencia de algo "natural", se esconde una estructura que permite que se perpetúe la desigualdad y, por tanto, la violencia machista.

Así lo ha desvelado el grupo focal, que se organizó en la Facultad de Ciencias de la Información de la Universidad Complutense de Madrid y contó con la participación de periodistas y de profesorado, sin formación en género, en la mayoría de los casos, que a lo largo de casi 4 horas de conversación y debate, concluyeron que los las políticas de género sobre medios de comunicación no son suficientes para abordar temas tan complejos.

Las y los profesionales de la comunicación reconocieron y pusieron de manifiesto que muchas actuaciones "inadecuadas" se deben a desconocimiento y escasa formación. Muchos y muchas profesionales no saben nada del movimiento feminista, ni siquiera que la Declaración de Derechos del Hombre y del Ciudadano no incluye a las mujeres, ni saben cuándo comenzaron a votar las mujeres en los países europeos y muchas veces no se lo plantean, porque no se habla de género en la escuela, ni en otros niveles de la enseñanza, incluyendo la Universidad. La Historia se explica siguiendo modelos que no incluyen la perspectiva de género, como en las escuelas y en la enseñanza secundaria y lo que no se sabe, no se puede contar.

Es necesario formar con perspectiva de género en las Universidades, especialmente a quienes trabajarán en el ámbito de la información, pero también en otras áreas de conocimiento. Para ello, hay que comenzar por la formación del profesorado universitario que no recibió en su momento la adecuada formación al no incorporar los estudios la perspectiva de género. Las Universidades deberían incorporar, vinculados a las Unidades de Igualdad creadas por ley, Observatorios de Género, que velen por la educación en igualdad y por la incorporación de la perspectiva de género en docencia e investigación. También es preciso incorporar asignaturas obligatorias específicas en género, y en el ámbito de la comunicación sobre "comunicación y género".

Las y los profesionales que ya están trabajando en medios de comunicación deberían recibir cursos de formación continua con perspectiva de género y en igualdad, impartidos por personas especializadas del ámbito universitario, con un marco teórico riguroso que permita la incorporación adecuada de conceptos básicos y de otros más complejos, vinculados a los procesos de socialización que construyen estereotipos y prejuicios. De esa forma, podrán transmitir la información desde una perspectiva que contribuya a comprender las causas de la desigualdad, interviniendo eficazmente para poner fin a esa lacra social que 
es la violencia de género.

Sólo se puede erradicar la violencia de género con inversión en igualdad. Las políticas de igualdad son fundamentales y es imprescindible que haya una política clara, con partidas presupuestarias adecuadas, para las Universidades, que formando a profesionales de todas las áreas de conocimiento tienen la posibilidad de intervenir activamente en la erradicación de la violencia de género. Esto sólo será posible con los recursos que permitan la formación de sus docentes y de sus investigadoras e investigadores para que, en cumplimiento de la legislación vigente, incorporen la perspectiva de género de manera transversal. La formación debe hacerse, además, desde un marco teórico feminista, poniendo en valor los estudios feministas y de género y reivindicando un lenguaje inclusivo, que nombre a las mujeres y las ponga en valor. Porque sólo lo que se nombra existe, y tratar de incluir a las mujeres en el masculino genérico crea confusión e impide la construcción de referentes, negando el valor de lo femenino y transmitiendo la idea equivocada de la igualdad implica la incorporación de las mujeres a los valores masculinos dominantes. Las visiones androcéntricas contribuyen a nuevas y sutiles formas de violencia.

\section{REFERENCIAS}

\section{LIBROS, CAPÍTULOS DE LIBRO O ENTRADA DE UN LIBRO DE CONSULTA, INFORMES TÉCNICOS, TESIS}

FUENTES, J.F. y GARÍ, P. (2013). Amazonas de la libertad. Mujeres liberales contra Fernando VII. Madrid: Marcial Pons Historia.

GARCÍA-BERRIO HERNÁNDEZ, T. (2008). Medidas de protección de la mujer ante la Violencia de Género. Claves para la igualdad. Madrid: Grupo Difusión.

GIL AMBRONA, A. (2008). Historia de la violencia contra las mujeres. Misoginia y conflicto matrimonial en España. Madrid: Cátedra.

GIL RUIZ, J.M. (2007). Los diferentes rostros de la violencia de género. Madrid: Dykinson.

LOSCERTALES ABRIL, F. y NÚÑEZ DOMÍNGUEZ, T. (2008). Los medios de comunicación con mirada de género. Instituto Andaluz de la Mujer: Consejería para la Igualdad y Bienestar Social.

MARÍN LÓPEZ, P. y LORENTE ACOSTA, M. (2008). La valoración del daño en las víctimas de la violencia de género. Madrid: Consejo General del Poder Judicial. 
MARTÍNEZ GARCÍA, E. (2008). La tutela judicial de la violencia de género. Madrid: Iustel e Instituto de la Mujer.

ORGA LARRÉS, J.C. (2008). Violencia de género. Mi experiencia como juez. Navarra: Editorial Aranzadi.

SUÁREZ OJEDA, M. (2012). Género y mujer desde una perspectiva multidisciplinar. Madrid: Editorial Fundamentos.

TAJAHUERCE ÁNGEL, I. (2014). Mujeres y Comunicación. Madrid: La Linterna Sorda.

\section{AUTORAS:}

\section{Isabel Tajahuerce Ángel}

Delegada del Rector para la Igualdad en la Universidad Complutense de Madrid. Profesora Contratada Doctora de la Universidad Complutense de Madrid, adscrita al Departamento de Historia de la Comunicación Social de la Facultad de Ciencias de la Información de la Universidad Complutense de Madrid. Asimismo, es integrante del Grupo de Investigación UCM "Cultura y Modelo Nórdico de Sociedad de la Información" y miembro del Instituto de Investigaciones Feministas UCM. Autora de varias decenas de artículos de alto impacto, capítulos de libro y libros en materia de género e historia de la comunicación social.

\section{Graciela Padilla Castillo}

Profesora en el Departamento de Periodismo III, Facultad de Ciencias de la Información, Universidad Complutense de Madrid. Doctora en Ciencias de la Información, con Premio Extraordinario de Doctorado, y Licenciada en Periodismo y Comunicación Audiovisual, con Premio Fin de Carrera. Ha completado su formación posdoctoral en la Universidad de California en Los Ángeles (UCLA). Sus líneas de investigación se centran en Ética audiovisual, Teoría de la Información, Ficción televisiva, Redes sociales y Redes profesionales y Estudios de Género. Es miembro del Instituto de Investigaciones Feministas (Universidad Complutense de Madrid).

http://scholar.google.es/scholar?hl=es\&q=graciela+padilla\&btnG=\&lr= http://orcid.org/0000-0003-1393-4817 